\title{
Surface Interaction and Corrosion Inhibition of Mild Steel in Hydrochloric Acid Using Pyoverdine, an Eco-Friendly Bio- molecule
}

\author{
K. M. Shainy ${ }^{1} \cdot$ P. Rugmini Ammal ${ }^{1} \cdot$ K. N. Unni ${ }^{2} \cdot$ Sailas Benjamin $^{2} \cdot$ \\ Abraham Joseph ${ }^{1}$
}

Received: 22 April 2016/Revised: 19 June 2016/Accepted: 22 June 2016/Published online: 5 July 2016

(C) Springer International Publishing Switzerland 2016

\begin{abstract}
Pyoverdine, an yellowish-green, water-soluble fluorescent siderophore, was predominantly produced by the species of Pseudomonas, P. aeruginosa, is used as a corrosion inhibitor for mild steel in $0.5 \mathrm{M} \mathrm{HCl}$, and its efficiency was studied by gravimetric method, electrochemical impedance spectroscopy and polarization techniques at temperatures of 303, 308 and $313 \mathrm{~K}$. Pyoverdine being a strong iron chelator shows excellent inhibition efficiency at all these temperature regions. The adsorption of pyoverdine on mild steel surface increases the charge transfer resistance and activation energy of metal corrosion. $97.55 \%$ of protection efficiency was reported for $10 \mathrm{ppm}$ inhibitor at $303 \mathrm{~K}$; the bacterial biofilm can protect the metal even at 308 and $313 \mathrm{~K}$, and efficiency reduced to only 73 and $68 \%$. Pyoverdine inhibited both anodic and cathodic reactions and hence worked as a mixed type inhibitor. The results of electrochemical studies also support this observation. The surface morphology of mild steel was examined with scanning electron microscopy and atomic force microscopy. The inhibitor got adsorbed on the metal surface, and the process of adsorption follows Langmuir and Temkin isotherms.
\end{abstract}

Keywords Pyoverdine - Mild steel · Acid solution · Adsorption · Polarization · EIS

Abraham Joseph

drabrahamj@gmail.com

1 Department of Chemistry, University of Calicut, Calicut University, Thenhipalam 673635, India

2 Department of Botany, University of Calicut, Calicut University, Thenhipalam 673635, India

\section{Introduction}

Corrosion is defined as a process by which materials are degraded/deteriorated due to the reaction with its environment. Mild steel stands as a backbone for a broad spectrum of industries, machineries, automotives, etc. To date, corrosion inhibition in steel has trigged significant academic and industrial concern. Corrosion inhibitors are substances that are added in small quantities to corrosive media to retard the corrosion rate. The surface interaction and the protection layer formation depend on the structure and concentration of inhibitors [1,2], microstructure of metal surface, temperature of exposure, $\mathrm{pH}$ of the reaction medium and the extent of immersion time [3-6].

Suitable inhibitors can protect materials from corrosion, especially in acid medium. Acid media are widely used in various industrial processes such as acid pickling of steel and iron, oil well acidification, chemical cleaning and processing. $\mathrm{HCl}$ is more cost effective, trouble free and efficient when compared to other mineral acids. The inhibitive efficiency of a material to a greater extent depends on its molecular structure. Most efficient and well-known acidic inhibitors are organic compounds containing heteroatoms like $\mathrm{O}, \mathrm{N}$ and $\mathrm{S}$ and $\pi$-donor systems. The inhibition action occurs by forming a donor-acceptor surface complex between the free or $\pi$-electrons of the inhibitors and vacant $\mathrm{d}$ orbital of metal atoms.

Organic inhibitors are very effective against corrosion; their hazardous effect detracts its wide usage. Unfortunately, most of the organic inhibitors are expensive, poisonous and environmentally non-benign. This has paved the need to develop cheap, non-toxic and environmentally benign inhibitors from natural sources. Green corrosion inhibitors are safe and degradable; moreover, they do not contain heavy metals or other hazardous compounds [7-10]. 
Several reports exist on the use of various plant extracts as green corrosion inhibitors. Reports are available that natural honey [11-14] and animal proteins can also serve as green inhibitors. Plant extract and animal protein can serve as a bank of natural products that are environmentally safe, cost effective, easily available and renewable. In the present work, we have demonstrated the corrosion inhibition efficiency of pyoverdines' novel strain of siderophore-producing bacterium, i.e. Pseudomonas aeruginosa BUP2 ( $\mathrm{Pa}$ BUP2) from the rumen of animal extract. Pyoverdines are a group of fluorescent siderophores having high affinity for iron. No reports are available in literature for the utilization of pyoverdine as corrosion inhibitor for mild steel [15]. Pyoverdines are peptide-derived primary siderophores, composed of three structural parts: an invariant dihydroxy quinoline chromophore conferring colour and fluorescence, an acyl moiety and a peptide side chain comprising 6-12 amino acids, some of them being unusual. Pyoverdines have three iron (III) binding sites; the peptide chain lodges two of these iron binding sites, and the catecholate group of the chromophore harbours the third one. The peptide moiety principally involved in receptor recognition, whose size and amino acid compositions are unique to each species. The structure of pyoverdine shows great variability among the species, and even between strains of the same species. Pyoverdines not only are iron chelators but act also as signalling molecules for virulence prevent iron toxicity due its overload and effectively scavenge hydroxyl and peroxyl radicals. Pyoverdine is a fluorescent molecule having colour imparting chromospheres, an acyl moiety and a variable peptide chain in the molecular structure. Pyoverdines have many advantages and can act as potential ligand in fluorescent quenching processes to demonstrate that the binding of $\mathrm{Fe}$ or $\mathrm{Cu}$ coordinately with the fluorescent material through heteroatoms. Pyoverdines have an outstanding ability to assimilate Fe(III) from its environment and take part in the iron mobilization in humans and in the treatment of iron diseases [16].

The present investigation is an attempt to explore the corrosion inhibition action of pyoverdine on mild steel in $0.5 \mathrm{M} \mathrm{HCl}$ at three temperature regions (303, 308 and $313 \mathrm{~K}$ ) by weight loss method, Tafel polarization and electrochemical impedance spectroscopy. The mechanism of inhibition was ascertained by scanning electron microscopy, adsorption studies and atomic force microscopy.

\section{Experimental}

\subsection{Materials and Methods}

The mild steel coupons of the following composition (wt \%) - C (0.20\%), Mn (1\%), P (0.03\%), S (0.02\%) and
Fe $(98.75 \%)$ - was employed in the study. The coupons of dimensions $2.8 \times 1.9 \mathrm{~cm}^{2}$ were cut and used as the samples or working electrodes. But only $1 \mathrm{~cm}^{2}$ area was exposed during every measurement. Before the measurement, each coupon was abraded using different-grade emery papers (600-1200 grade) and then subjected to ensure mirror bright finish by the action of buffing machine attached with a cotton wheel and a fibber wheel having buffing soap. Then the coupons were degreased with acetone and washed with distilled water.

The experimental medium was prepared from reagent grade $\mathrm{HCl}$ (E. Merck) and doubly distilled water. All the experiments were performed in aerated medium at different temperatures $(303,308$ and $313 \mathrm{~K})$.

\subsection{Extraction of Inhibitor}

Pyoverdine separated from animal extract was used as the inhibitor for the study. The Rumen contents were collected aseptically from slaughter house in screw-capped tubes and extracted [17]. For the isolation of pyoverdine, $10 \mathrm{~g}$ of collected Rumen content was taken, and $10 \mathrm{ml}$ sterile double distilled water was added and centrifuged at $800 \times g$ for $277 \mathrm{~K}$ at $5 \mathrm{~min}$. The supernatant liquid obtained as above was serially diluted (up to $10^{-6}$ ) with pre-sterilized double distilled water [18, 19]. This diluted sample was spread aseptically on nutrient agar medium ( $\mathrm{pH} 7.2)$ in Petri dishes at $310 \mathrm{~K}$ for $48 \mathrm{~h}$. The isolated colonies so obtained were examined for the presence of Pseudomonas sp. The purity was confirmed by sub-culturing. The reported structure of pyoverdine [20] was reproduced using Chem Bio Draw Ultra 12.0, which is shown in Fig. 1

\subsection{Characterization of Pyoverdine}

Spectroscopic techniques such as FTIR and Electronic spectroscopic measurements were used to characterize PVD and its chelating ability on mild steel surface under

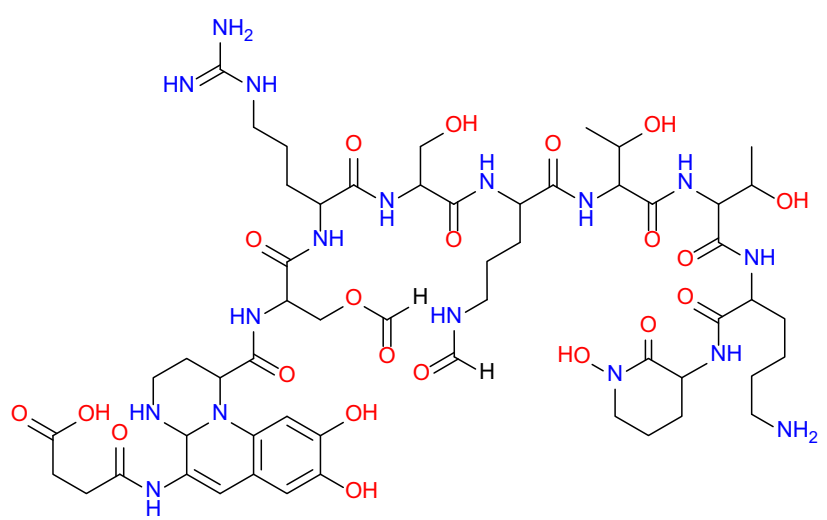

Fig. 1 The structure of the inhibitor pyoverdine 
$0.5 \mathrm{M} \mathrm{HCl}$ solutions. JASCO FTIR 400-4000 spectrophotometer and JASCO -UV-VIS550 spectrophotometer were used for absorption spectroscopic studies.

\subsection{Gravimetric Measurements}

The inhibition efficiency of the inhibitor was determined using classical gravimetric weight loss technique at room temperature. The mild steel coupons cleaned as per ASTM standard were accurately weighed and immersed in the test solution with and without inhibitor for different time intervals. The specimens were taken out carefully, cleaned, dried and weighed. From the weight loss of the inhibited and uninhibited solutions, the corrosion rate and hence the inhibition efficiency can be calculated.

\subsection{Electrochemical Measurements}

The electrochemical impedance (EIS) and potentiodynamic polarization studies were carried out using Gill AC instruments (ACM, UK model no. 1745), and the data were analysed by fitting the impedance and polarization data with commercially available Gill ACM software. The instrument consists of a three electrode corrosion cell with platinum foil used as the auxiliary electrode and saturated calomel electrode as the reference electrode. The working electrode was the square (for $303 \mathrm{~K}$ ) and circular (for 308 and $313 \mathrm{~K}$ ) coupons of mild steel. The EIS measurements were carried out in a frequency range of $0.1-10,000 \mathrm{~Hz}$ with amplitude of $10 \mathrm{mV}$. The polarization measurements were recorded with a scan rate of $1 \mathrm{mV} / \mathrm{s}$ in the potential range from -250 to $+250 \mathrm{mV}$. The mild steel coupons were immersed into the test solution for $60 \mathrm{~min}$ to establish a steady-state open circuit potential $\mathrm{E}_{\mathrm{ocp}}$.

\subsection{Adsorption Studies}

Inhibitive ability of a compound to a greater extent depends on its adsorption on metal surface. Various adsorption isotherms like Langmuir, Temkin, Frumkin and Freundlich were tested. Langmuir and Temkin were found to give a more linear fit. The values of regression coefficients $\left(R^{2}\right)$ confirmed the validity of the approach.

\subsection{Surface Characterization (SEM)}

The surface characterization of metal specimen was carried out by scanning electron microscopy (Digital microscope imaging scanning electron microscope model SU6600, Serial No.HI-2102-0003) in the presence and absence of inhibitor. All micrographs were recorded at $\times 500$ magnification. The metal specimens were immersed in acid solution containing optimum concentration of inhibitor for $5 \mathrm{~h}$, and then they were removed, rinsed with acetone and dried and used for measurements.

\subsection{Atomic Force Microscopy (AFM)}

Atomic force microscopy provides topographical image of mild steel sample. It is highly accurate and dependable method for the surface study. The polished mild steel samples were collected and immersed in two beakers containing $0.5 \mathrm{M} \mathrm{HCl}$ solution and optimum concentration of inhibitor and was kept for $5 \mathrm{~h}$. The roughness of sample without and with inhibitor was measured.

\section{Results and Discussion}

\subsection{IR Spectra}

A deep insight into the possibility of complex formation between the inhibitor and the metal was analysed by the FTIR spectroscopic measurements. Pyoverdine can form a strong coordination complex with mild steel surface through its bonding with $\mathrm{Fe}^{3+} / \mathrm{Fe}^{2+}$ ions. The characteristic absorption bands and their assignments to specific molecular groups are presented in Table 1. The formation of a bidentate coordination complex on the metal surface supported the study of relative intensities of functional groups. The $\mathrm{O}-\mathrm{H}$ group on the catechol-like group of 2,3-diamino6,7-dihydroxyquinoline-type chromospheres changes to $3424 \mathrm{~cm}^{-1}$ indicating that $\mathrm{O}-\mathrm{H}$ is a part of coordination to the $\mathrm{Fe}$ surface. The $\mathrm{C}=\mathrm{O}$ stretching band at $1638 \mathrm{~cm}^{-1}$ indicates the involvement of such groups in complex formation. The nicotinic hydroxamate group in the molecule also has taken part in bonding. In addition, amide group of peptide also changes to recognize with the peak at $1401 \mathrm{~cm}^{-1}$. C-O stretching vibrations of catecholate-like ligands appeared as a strong band at $1114 \mathrm{~cm}^{-1}$, and it is coordinatively bound to metal ions to form Fe-pyoverdine (ferripyoverdine) $[15,21]$. The band at $617 \mathrm{~cm}^{-1}$ corresponding to $\mathrm{Fe}-\mathrm{O}$ stretching reveals the presence of $\mathrm{Fe}-\mathrm{O}$ coordinate bond. The band at 3235 and $1401 \mathrm{~cm}^{-1}$ shows the major contributions of $\mathrm{N}-\mathrm{H}$ stretching and bending vibrations of amides on the peptide chain bonded to Fe. Due to the formation of strong coordination complex, the corrosion of mild steel surface from the $\mathrm{HCl}$ solution can be effectively prevented even at low concentrations of pyoverdine such as 2, 4, 6, 8 and $10 \mathrm{ppm}$. Figure 2 exhibits the experimental FTIR spectrum of pyoverdine and pyoverdine-coated mild steel film. The chelating ability of $\mathrm{Fe}^{3+} / \mathrm{Fe}^{2+}$ with PVD is evident from the weakening of the stretching frequencies of pyoverdine-coated film. 
Table 1 Assignments for the IR absorption band to the corresponding molecular groups recorded during pyoverdine and pyoverdine coating on mild steel in $0.5 \mathrm{M} \mathrm{HCl}$ on $303 \mathrm{~K}$

\begin{tabular}{lll}
\hline Pyoverdine/wave number $\left(\mathrm{cm}^{-1}\right)$ & Fe coating/wave number $\left(\mathrm{cm}^{-1}\right)$ & Molecular groups \\
\hline 3411 & 3424 & $\mathrm{v}(\mathrm{O}-\mathrm{H})$ stretching \\
3135 & 3235 & $\mathrm{v}(\mathrm{N}-\mathrm{H})$ stretching \\
1639 & 1638 & $\mathrm{v}(\mathrm{N})$ \\
& & $\mathrm{v}(\mathrm{N}-\mathrm{H})$ bending \\
1400 & 1401 & $\mathrm{v}(\mathrm{C}=\mathrm{C})$ \\
1384 & 1384 & $\mathrm{v}(\mathrm{C}-\mathrm{O}$ \\
1114 & 1192 & $\mathrm{v}(\mathrm{Fe}-\mathrm{O})$ \\
& 617 & $\mathrm{v}(\mathrm{Fe}-\mathrm{N})$ \\
\hline
\end{tabular}

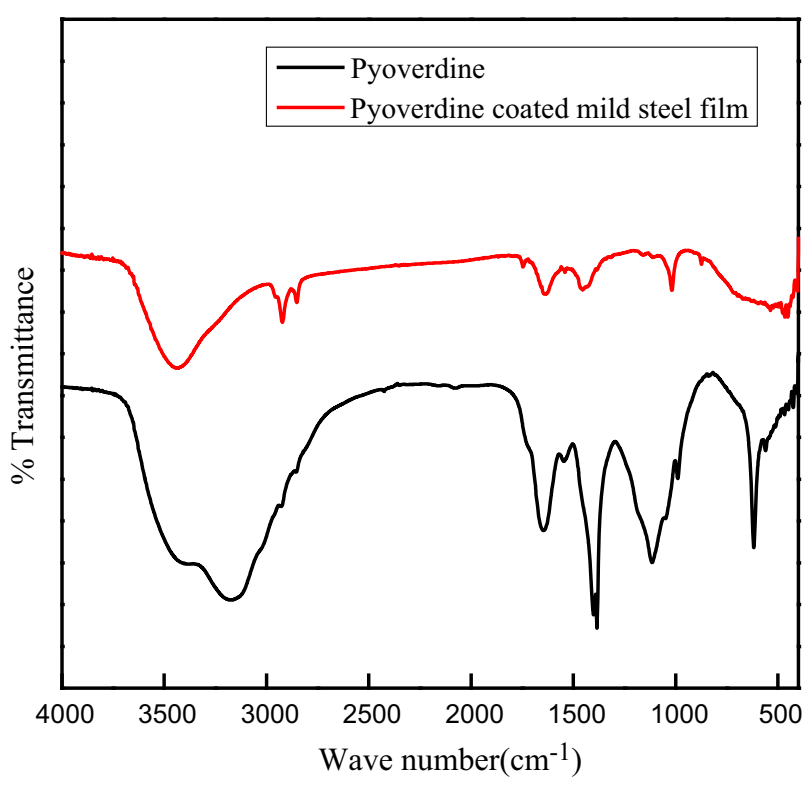

Fig. 2 FTIR Spectra of pyoverdine and film obtained from the surface of mild steel in $0.5 \mathrm{M} \mathrm{HCl}$ solution in the presence of pyoverdine

\subsection{Electronic Spectra}

The UV-Visible spectral studies were used to analyse the shift in the value of $\lambda_{\max }$ (absorbance maximum) when the medium of dispersion changes from aqueous to acidic. The UV-Visible absorption of simulated pyoverdine in $0.5 \mathrm{M}$ $\mathrm{HCl}$ solution is shown in Fig. 3. The major absorption peaks of these are centred towards the wavelengths of 410 , 450, 680 and $848 \mathrm{~nm}$, respectively. The solvent polarity and the $\mathrm{pH}$ affect the absorption spectrum, and red-shift occurred due to high $\mathrm{pH}$ in the corrosive medium.

\subsection{Weight Loss Measurements}

Weight loss method is the accurate and easiest way to determine the rate of corrosion and percentage inhibition

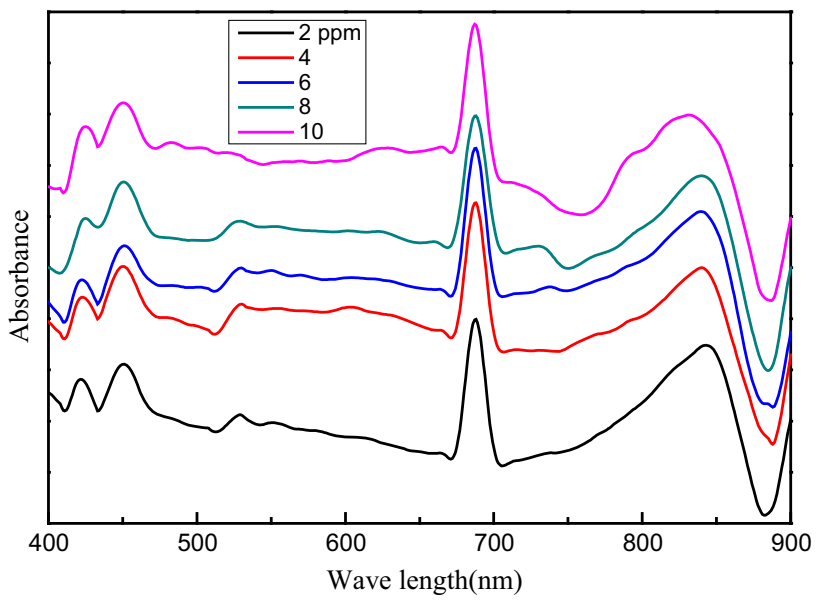

Fig. 3 The emission spectra of pyoverdine in $0.5 \mathrm{M} \mathrm{HCl}$ solution

efficiency. Various concentrations of pyoverdine (2, 4, 6, 8 and $10 \mathrm{ppm}$ ) were collected and dissolved in $0.5 \mathrm{M} \mathrm{HCl}$. The mild steel samples were immersed in inhibited solution and allowed to react for 24, 48, 72 and $96 \mathrm{~h}$. The sample was taken out from the solution and washed with double distilled water and then acetone dried in an air oven. The weight loss of every sample was measured at each time interval and recorded the difference. A blank determination was also conducted for the comparison of inhibition efficiency of pyoverdine. The corrosion inhibition efficiency was calculated from the equation

IE $\%=\frac{W_{0}-W}{W_{0}} \times 100$,

where $W_{0}$ and $W$ represent the weight loss of mild steel in the absence and presence of pyoverdine. Weight loss of mild steel coupons in the presence of various concentrations of pyoverdine (2, 4, 6, 8 and $10 \mathrm{ppm})$ after immersion in $0.5 \mathrm{M} \mathrm{HCl}$ is measured, and the results are presented as bar diagram in Fig. 4 (variation in IE \% with inhibitor concentration at different exposure periods are shown in Fig. 4). 


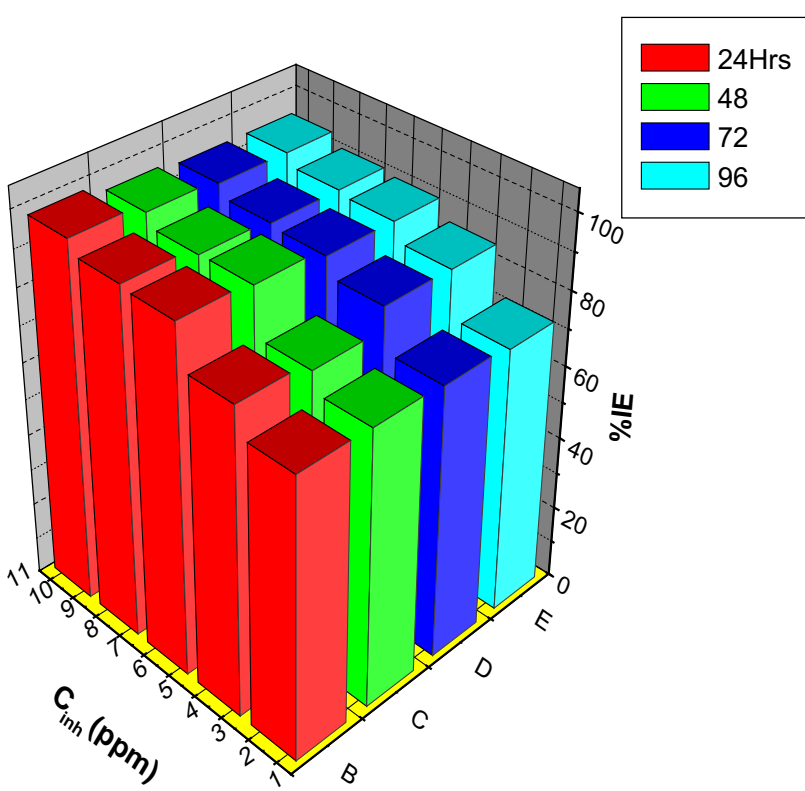

Fig. 4 Weight loss of mild steel coupons in the presence of various concentrations of pyoverdine (2, 4, 6, 8 and $10 \mathrm{ppm})$ after immersion in $0.5 \mathrm{M} \mathrm{HCl}$

\subsection{Electrochemical Impedance Spectroscopy (EIS)}

EIS is a highly dependable tool to elucidate the mechanism occurring at the mild steel/electrolyte interface. This electrochemical technique is based on the examination of the impedance of double layer formed at the interface of mild steel/electrolyte [22, 23]. The interface acts as a capacitor constituting the mild steel surface as one electrode and the ions in the electrolyte as the other. Outer Helmholtz plane is the closest approach of the centres of these ions and adsorbed ions constitutes the inner Helmholtz plane. The ions are arranged in a diffuse layer outside the inner Helmholtz plane, and these function as a capacitor in series with the Helmholtz layer [24, 25].

Normally accepted circuit for metal/electrolyte interface is Randles circuit (Fig. 5). The impedance behaviour can be compared to a parallel combination of a capacitor $C_{\mathrm{dl}}$ and a resistor $R_{\mathrm{t}}$ and both in series combination with another resistor $R_{\mathrm{s}}$. Charge transfer resistance can be considered the difference in the real impedance at higher and lower frequencies.

The impedance measurement is carried out in $0.5 \mathrm{M}$ $\mathrm{HCl}$ after 1 hour of immersion. The Nyquist plots of mild steel in $\mathrm{HCl}$ in the presence of $10 \mathrm{ppm}$ pyoverdine at 303, 308 and $313 \mathrm{~K}$ are shown in Fig. 6. The impedance spectra reveal the presence of a large capacitive loop throughout the studied frequency range. Addition of inhibitor drastically changes the impedance spectra. The impedance of the inhibitor system increases with the inhibitor concentration,

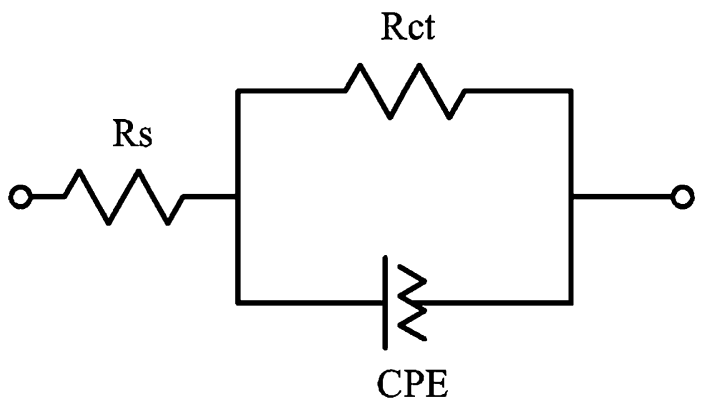

Fig. 5 Randles circuit

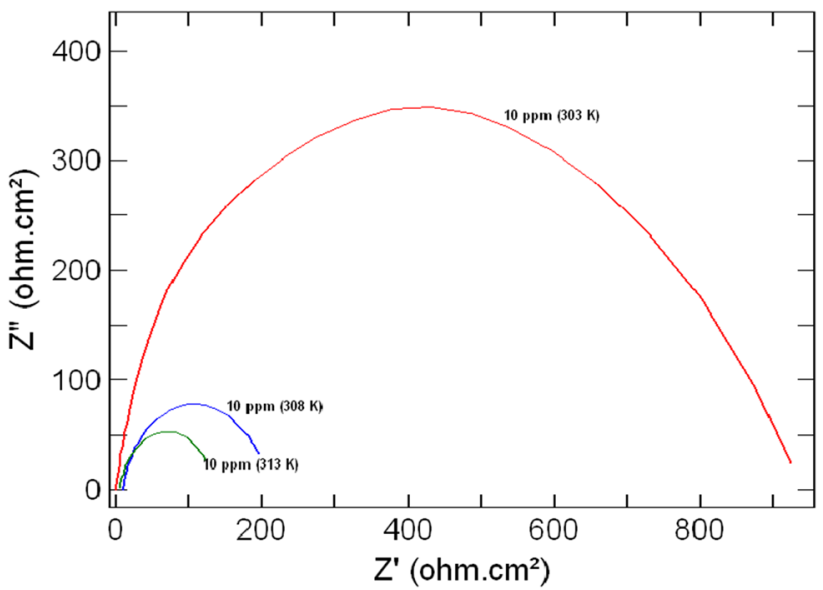

Fig. 6 Nyquist plots for mild steel corrosion in $0.5 \mathrm{M} \mathrm{HCl}$ in the presence of $10 \mathrm{ppm}$ pyoverdine at 303,308 and $313 \mathrm{~K}$

and maximum impedance is obtained for $10 \mathrm{ppm}$ of pyoverdine.

A perfect semi-circle is not observed in the Nyquist plot, as expected from the AC impedance theory. Depressed or suppressed semi-circles are seen. This behaviour can be explained as follows: The electronic equivalent circuit models are fabricated so as to fit the equivalent circuit setup and give a perfect Nyquist plot in real condensers of dummy cells; the charge distribution is controlled by the electrons. The dummy cells comprise two metallic plates. Meanwhile, in a corrosion system, a double layer is formed, and this double layer at the metal/electrolyte interface does not act as a perfect condenser. For the corrosion system, the charge distribution is controlled by ions. Ions being larger than electron occupy large volume of the double layer [26].

The double-layer capacitance values can be obtained from the Nyquist plot using the equation

$C_{\mathrm{dl}}=\frac{1}{2 \pi f_{\max } R_{\mathrm{ct}}}$,

where $f_{\max }$ is the frequency at which the imaginary component is maximum on the Nyquist plot. The variation of $C_{\mathrm{dl}}$ with the concentrations of pyoverdine is presented in 
Table 2 Electrochemical impedance data for mild steel corrosion in $0.5 \mathrm{M} \mathrm{HCl}$ in the presence and absence of pyoverdine at 303 , $308,313 \mathrm{~K}$

\begin{tabular}{|c|c|c|c|c|c|c|c|}
\hline Acid conc $(\mathrm{M})$ & Temp. (K) & Pyoverdine conc. (ppm) & $R_{\mathrm{ct}}\left(\Omega \mathrm{cm}^{2}\right)$ & $C_{\mathrm{dl}}\left(\mu \mathrm{F} / \mathrm{cm}^{2}\right)$ & $I_{\text {corr }}\left(\mu \mathrm{A} / \mathrm{cm}^{2}\right)$ & C R (mm/year) & IE \% \\
\hline & 303 & Blank & 19.47 & 431.7 & 1.340 & 611.41 & - \\
\hline & & 2 & 82.20 & 87.23 & 0.3174 & 144.80 & 76 \\
\hline & & 4 & 151.80 & 72.27 & 0.1719 & 78.42 & 87 \\
\hline & & 6 & 467.30 & 61.59 & 0.0558 & 25.47 & 95 \\
\hline & & 8 & 640.80 & 48.36 & 0.0407 & 18.58 & 96 \\
\hline & & 10 & 778.90 & 37.68 & 0.0335 & 15.28 & 97 \\
\hline \multirow[t]{12}{*}{0.5} & 308 & Blank & 50.57 & 93.41 & 0.5159 & 235.41 & - \\
\hline & & 2 & 66.95 & 143.90 & 0.3896 & 177.81 & 24 \\
\hline & & 4 & 73.32 & 101.11 & 0.3558 & 162.33 & 31 \\
\hline & & 6 & 91.96 & 122.80 & 0.2837 & 129.00 & 45 \\
\hline & & 8 & 114.10 & 122.70 & 0.2286 & 104.31 & 55 \\
\hline & & 10 & 193.70 & 98.06 & 0.1347 & 61.45 & 73 \\
\hline & 313 & Blank & 11.98 & 501.70 & 2.1780 & 993.61 & - \\
\hline & & 2 & 14.74 & 728.41 & 1.7701 & 807.61 & 18 \\
\hline & & 4 & 18.17 & 608.53 & 1.7200 & 784.72 & 21 \\
\hline & & 6 & 23.76 & 468.51 & 1.0980 & 501.01 & 49 \\
\hline & & 8 & 27.63 & 220.41 & 0.9442 & 430.81 & 56 \\
\hline & & 10 & 38.78 & 127.84 & 0.6030 & 306.91 & 68 \\
\hline
\end{tabular}

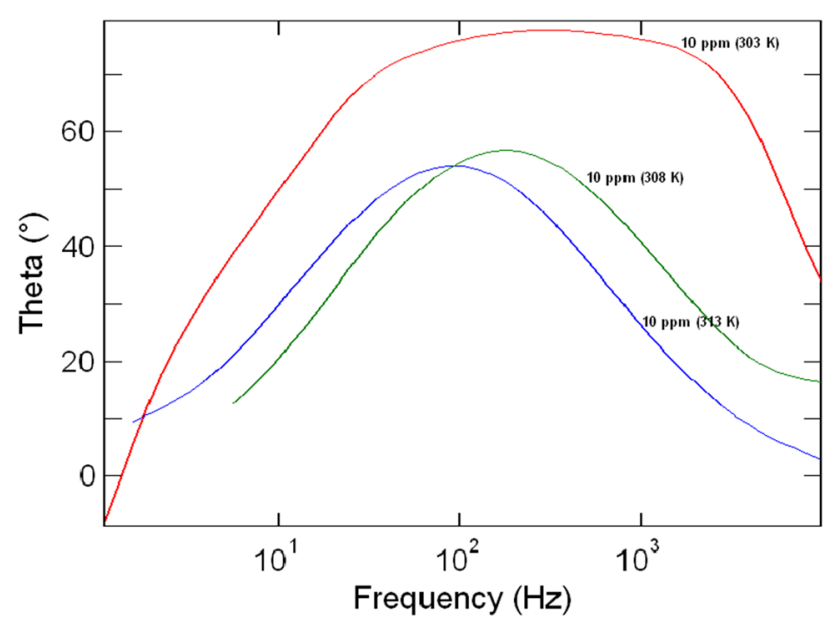

Fig. 7 Bode plots for mild steel corrosion in $0.5 \mathrm{M} \mathrm{HCl}$ in the presence of $10 \mathrm{ppm}$ pyoverdine at 303,308 and $313 \mathrm{~K}$

Table 2. It is clear from the table that the value of $C_{\mathrm{dl}}$ in the presence of various concentrations of pyoverdines is less than that of blank solution. This suggests the possibility of strong adsorption of pyoverdine on the interface. Moreover, there is a decrease in $C_{\mathrm{dl}}$ values with the increase in temperature of the reaction medium. Therefore, the displacement of water molecule by the adsorption of pyoverdine was greatly understood. This trend can be attributed to the decrease in local dielectric constant or increases in the thickness of electrical double layer. Moreover, from Fig. 6, it is clear that the diameter of the

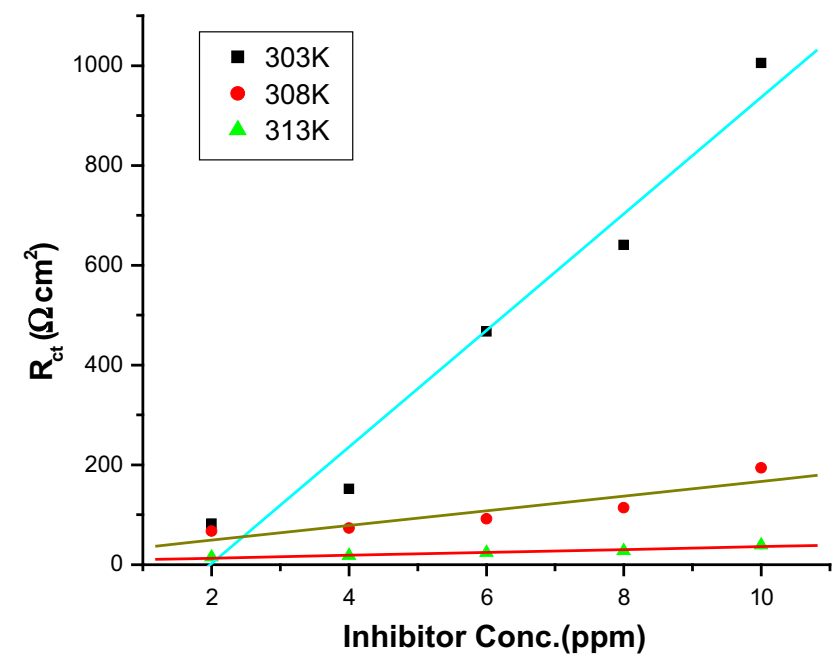

Fig. 8 Comparison of charge transfer resistance and concentration of PVD on various temperatures

capacitive loop of $10 \mathrm{ppm}$ pyoverdine at $303 \mathrm{~K}$ is greater than that at 308 and $313 \mathrm{~K}$, respectively. This suggests that the impedance of pyoverdine and temperature are inversely related.

The electrochemical parameters such as $R_{\mathrm{ct}}, C_{\mathrm{dl}}, I_{\text {corr }}$, corrosion rate and IE \% for mild steel obtained from the EIS measurements are summarized in Table 2. Fig. 7 demonstrates the Bode plots obtained for mild steel samples in $10 \mathrm{ppm}$ inhibitor solution at 303,308 and $313 \mathrm{~K}$, respectively.

The constant phase element (CPE) corresponding to the double-layer interface between mild steel and solution. 


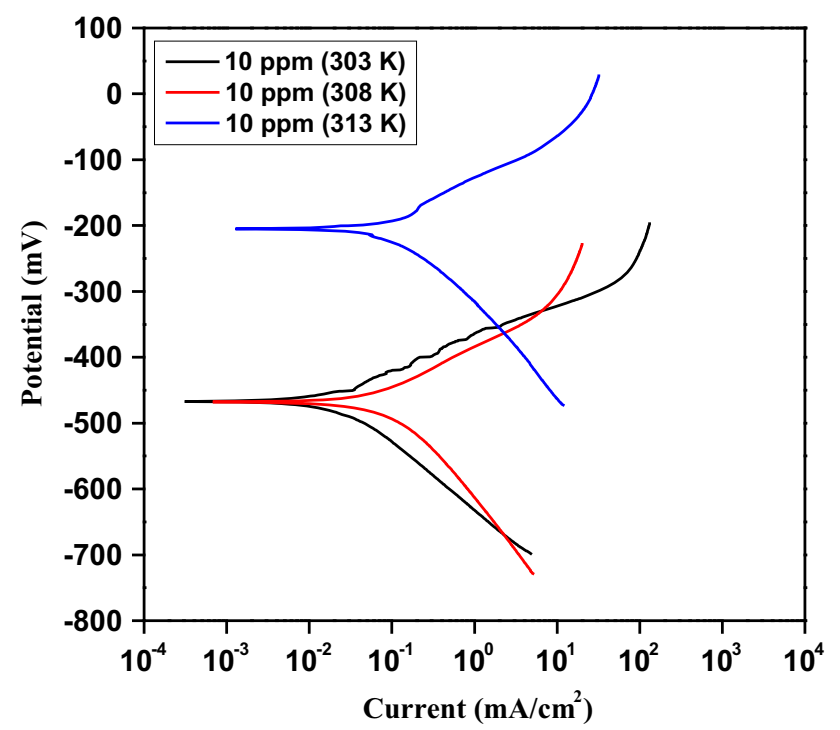

Fig. 9 Tafel plots for mild steel corrosion in $0.5 \mathrm{M} \mathrm{HCl}$ in the presence of $10 \mathrm{ppm}$ pyoverdine at 303,308 and $313 \mathrm{~K}$

CPE can be employed to visualize the suppression phenomenon which can be related to the inhomogeneity of surface, frequency dispersion and adsorbed layers. Table 2 clearly reveals that the value of $R_{\mathrm{ct}}$ varies linearly with the concentration of inhibitor. This trend affirms the formation of pyoverdine layer on the surface. It also implies that charge transfer process is impeded from time when the uncovered surface available for corrosion is receding due to the adsorption of molecules at the mild steel/solution interface [27]. It is to be noted that the $R_{\mathrm{ct}}$ values indicate the bonding interaction between the surface of the mild steel and the inhibitor molecule.

The inhibition efficiency can be calculated from EIS, using the equation

$\operatorname{IE}(\%)=\frac{R_{\mathrm{ct}}^{*}-R_{\mathrm{ct}}}{R_{\mathrm{ct}}^{*}} \times 100$,

where $R_{\mathrm{ct}}^{*}$ and $R_{\mathrm{ct}}$ are the charge transfer resistance in the presence and absence of pyoverdine in corrosive medium. $R_{\mathrm{ct}}^{*}$ is inversely related to the corrosion rate. The plots for the comparison of charge transfer resistance and concentration of pyoverdine on various temperatures are shown in Fig. 8. From Fig. 8, it is clear that when the concentration of pyoverdine increases from $2 \mathrm{ppm}$ to $10 \mathrm{ppm}$, the inhibition efficiency also increases. The maximum inhibition efficiency of $97.55 \%$ for $10 \mathrm{ppm}$ is observed at $303 \mathrm{~K}$. But it was reduced to $73 \%$ on increasing the temperature to $308 \mathrm{~K}$ and $68 \%$ on further increasing the temperature to $313 \mathrm{~K}$. So the chelating ability of pyoverdine with $\mathrm{Fe}^{2+}$ / $\mathrm{Fe}^{3+}$ diminishes slowly with rise in temperature, and hence, the protection efficiency of mild steel decreases. This result strongly suggests that pyoverdines are a good corrosion inhibitor for mild steel at $303 \mathrm{~K}$.

\subsection{Tafel Polarization}

The Tafel polarization curves for mild steel in $0.5 \mathrm{M} \mathrm{HCl}$ solution at 303,308 and $313 \mathrm{~K}$ in the presence and absence of pyoverdine were recorded. Among these, the Tafel plots

Table 3 Polarization data for mild steel corrosion in $0.5 \mathrm{M} \mathrm{HCl}$ in the presence and absence of pyoverdine at 303,308 and $313 \mathrm{~K}$

\begin{tabular}{|c|c|c|c|c|c|c|c|c|}
\hline Acid conc. (M) & Temp. (K) & Pyoverdine conc. (ppm) & $E_{\text {Corr. }}(\mathrm{mV})$ & $\beta_{\mathrm{a}}(\mathrm{mV} / \mathrm{dec})$ & $\beta_{\mathrm{c}}(\mathrm{mV} / \mathrm{dec})$ & $I_{\text {corr. }}\left(\mathrm{mA} / \mathrm{cm}^{2}\right)$ & $\mathrm{CR}$ (mm/year) & IE \% \\
\hline & 303 & Blank & -416.18 & 56.08 & 58.27 & 0.8151 & 79.34 & - \\
\hline & & 2 & -462.97 & 29.69 & 26.22 & 0.2445 & 23.61 & 70 \\
\hline & & 4 & -460.13 & 36.38 & 31.60 & 0.1227 & 12.03 & 84 \\
\hline & & 6 & -445.11 & 31.50 & 38.34 & 0.0673 & 5.26 & 93 \\
\hline & & 8 & -457.32 & 37.99 & 35.53 & 0.0447 & 3.72 & 95 \\
\hline & & 10 & -468.17 & 22.35 & 23.41 & 0.0254 & 2.77 & 96 \\
\hline \multirow[t]{12}{*}{0.5} & 308 & Blank & -476.80 & 68.68 & 66.00 & 0.5259 & 73.65 & - \\
\hline & & 2 & -484.39 & 48.52 & 48.05 & 0.3735 & 54.29 & 26 \\
\hline & & 4 & -481.39 & 66.28 & 102.29 & 0.6789 & 49.85 & 32 \\
\hline & & 6 & -483.24 & 48.05 & 42.40 & 0.1917 & 43.41 & 41 \\
\hline & & 8 & -472.37 & 30.09 & 35.20 & 0.2801 & 32.78 & 55 \\
\hline & & 10 & -468.63 & 24.65 & 58.03 & 0.5501 & 20.06 & 72 \\
\hline & 313 & Blank & -287.02 & 71.07 & 86.53 & 1.1435 & 345.18 & - \\
\hline & & 2 & -261.80 & 107.25 & 110.22 & 1.6179 & 293.57 & 14 \\
\hline & & 4 & -169.91 & 99.69 & 119.96 & 1.1730 & 262.29 & 24 \\
\hline & & 6 & -274.24 & 79.80 & 122.77 & 0.4078 & 168.09 & 46 \\
\hline & & 8 & -349.48 & 84.92 & 80.04 & 0.3269 & 149.19 & 57 \\
\hline & & 10 & -367.21 & 81.44 & 87.13 & 1.3751 & 105.26 & 69 \\
\hline
\end{tabular}



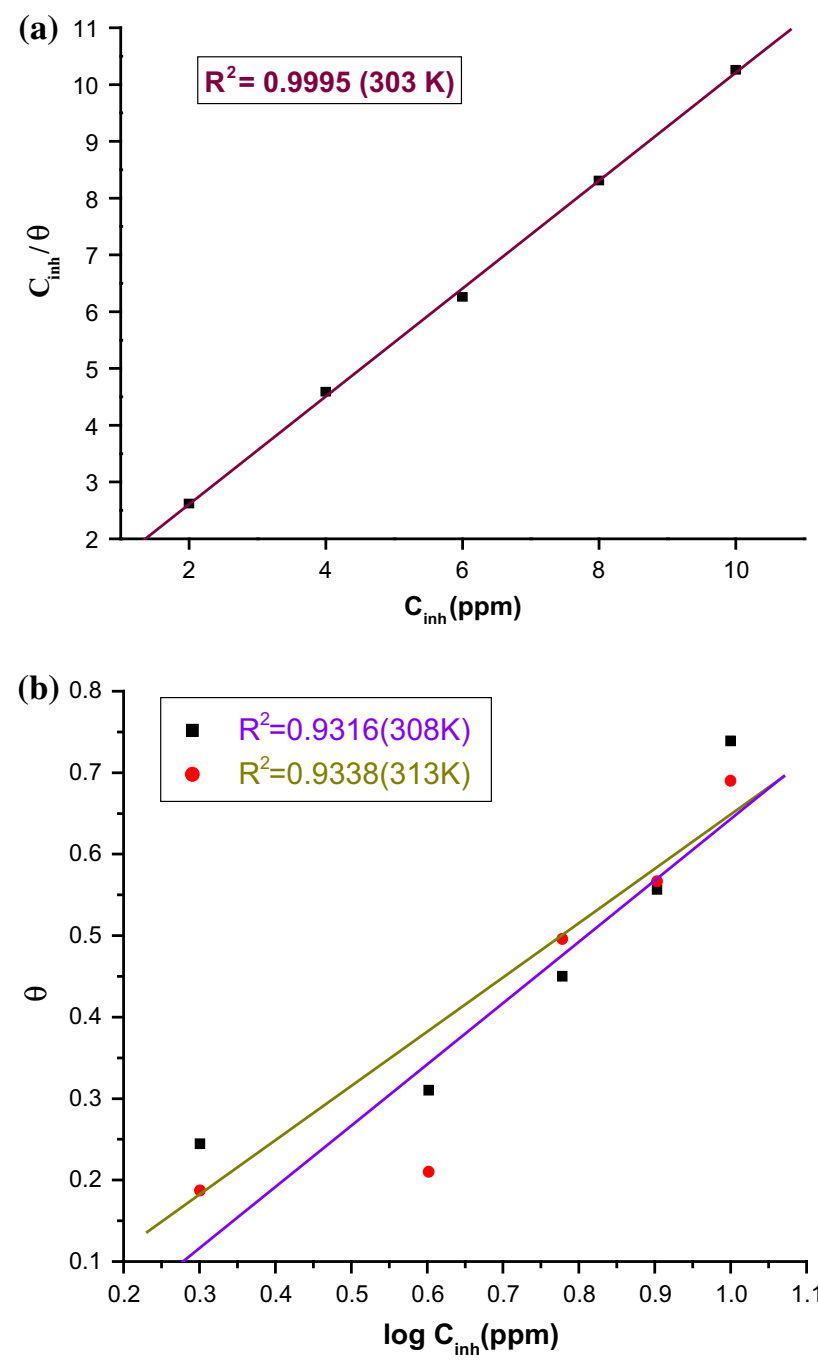

Fig. 10 The value of regression coefficients and the corresponding temperatures for a Langmuir and $\mathbf{b}$ Temkin adsorption isotherms

for $10 \mathrm{ppm}$ pyoverdine corresponding to the above temperature regions are shown in Fig. 9. The electrochemical parameters such as corrosion potential $\left(E_{\text {corr }}\right), I_{\text {corr }}$ and cathodic and anodic Tafel slopes $\left(\beta_{\mathrm{a}}, \beta_{\mathrm{c}}\right)$ and corrosion rate (CR in $\mathrm{mm} /$ year) are presented in Table 3.

The percentage inhibition efficiency (IE \%) was calculated from the equation

$\operatorname{IE}(\%)=\frac{I_{\text {corr }}^{*}-I_{\text {corr }}}{I_{\text {corr }}^{*}} \times 100$,

where $I_{\text {corr }}^{*}$ and $I_{\text {corr }}$ represent the corrosion current densities of the inhibited and uninhibited steel surface.

When the concentration of pyoverdine increases, there was a noticeable decrease in the corrosion rate. There is the shifting of Tafel polarization lines to the lower value and prevention of the cathodic and anodic reaction on mild steel electrode. These points are clearly understood by examining Table 3. IE \% increases, and corrosion current density decreases with the increase in concentration of pyoverdine.

Usually in acidic solution, dissolution of metal from the electrode material is the anodic reaction and discharge of $\mathrm{H}^{+}$ions to $\mathrm{H}_{2}$ gas or reduced $\mathrm{O}_{2}$ is the cathodic reaction. Pyoverdine affects both cathodic and anodic reactions of mild steel, and this trend increases with the increase in concentration. From the Tafel plot, it is clear that $E_{\text {corr }}$ value increases with the increase in concentration of pyoverdine and shifts towards the positive direction, since the anodic metal dissolution and cathodic hydrogen evolution decrease slowly [28]. Similarly, when the inhibitor concentration increases, the corrosion current density reduces to lower value. Moreover, the characterisation of cathodic and anodic behaviour of inhibition was predicted by the displacement of corrosion potential of inhibited solution within $\pm 80 \mathrm{mV}$ with respect to that of uninhibited solution $[29,30]$. The inhibitor pyoverdine has recorded a displacement of corrosion potential smaller than $85 \mathrm{mV}$ with respect to uninhibited solution which confirms the mixed type inhibition by preventing the both cathodic and anodic reactions.

Tafel constants $\beta_{\mathrm{a}}$ and $\beta_{\mathrm{c}}$ are not much deviated in the presence of pyoverdine with respect to the uninhibited medium, which indicates that the mechanism of adsorption is not affected by cathodic and anodic constants. It is simply acting as an adsorbent on the mild steel surface and blocking the active surface sites [31]. From Table 3, it is evident that pyoverdine is a mixed type inhibitor, and maximum inhibition efficiency observed for $10 \mathrm{ppm}$ pyoverdine was $96 \%$, that is, when the concentration of pyoverdine increases, more number of molecules get adsorbed on the mild steel surface and give a better coverage or barrier. The inhibition efficiency derived from Tafel plot and EIS measurements are comparable.

\subsection{Adsorption Studies}

An attempt to correlate the adsorption data using various isotherms provides an insight into the plausible mode of adsorption. The adsorption data were fitted with frequently used adsorption isotherm such as Langmuir, Temkin and Freundlich. The phenomenon of adsorption is influenced to a greater extent by the chemical structure of inhibitors, electron density and polarizability of functional group which can be evaluated by the measurement of inhibition efficiency [32-34]. The inhibitive ability of a substance depends on its extent of adsorption. Among the studied isotherms, Langmuir isotherm provided the best description for the adsorption behaviour at room temperature. Langmuir isotherm can be described by the equation 
Fig. 11 SEM images of mild steel specimens: a bare mild steel, $\mathbf{b}$ in $0.5 \mathrm{M} \mathrm{HCl}$ and $\mathbf{c}$ in $0.5 \mathrm{M} \mathrm{HCl}$ with pyoverdine
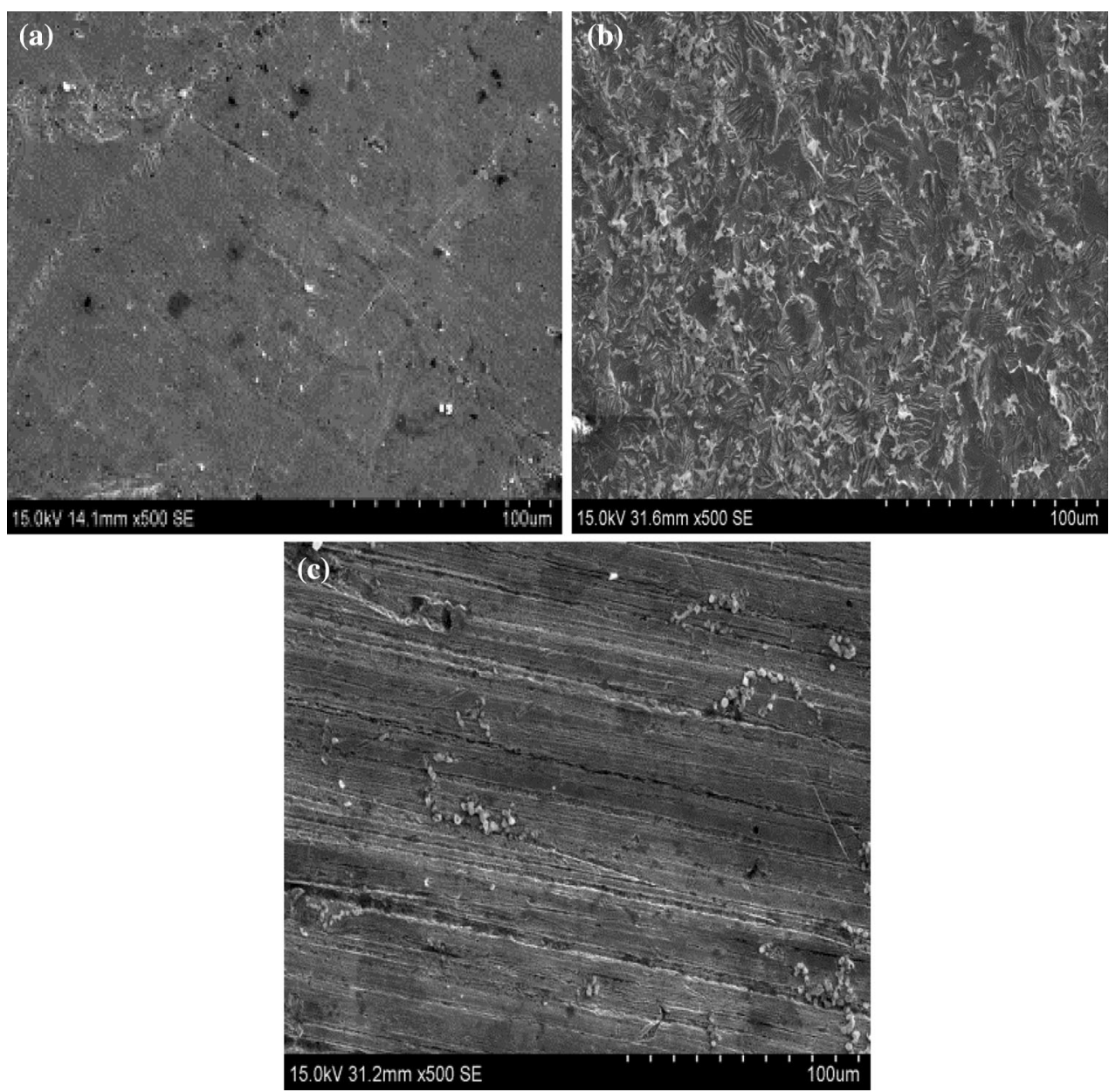

$\frac{C_{\mathrm{inh}}}{\theta}=C_{\mathrm{inh}}+\frac{1}{K_{\mathrm{ads}}}$,

where $C_{\mathrm{inh}}$ represents the concentration of inhibitor in ppm. Langmuir isotherms are based on the assumption that the adsorption sites are equivalent, and each site can adsorb one molecule. The linear plot of $C_{\mathrm{inh}} \mathrm{Vs} \theta$ confirms that the adsorption mode is Langmuir. IE varies linearly with the concentration of pyoverdine as can be seen from the surface coverage values $(\theta)$ of pyoverdine between $C / \theta$ and $\mathrm{C}_{\mathrm{inh}}$ for different concentrations of inhibitor in the presence and absence of pyoverdine. The values of regression coefficient calculated from the least square method from the origin software confirms the formation of thick monolayer of pyoverdine on the mild steel surface, and hence, further interaction between inhibitors can be ignored. As the temperature increases, the isotherm deviated from Langmuir and approaches to Temkin at 308 and $313 \mathrm{~K}$, respectively. The equation of Temkin isotherm can be represented as

$\theta=\ln K C+\frac{1}{f}$
From the obtained linear plot, the equilibrium constant $\left(K_{\text {ads }}\right)$ for the adsorption process can be evaluated. The standard Gibbs free energy of adsorption $\left(\Delta G_{\mathrm{ads}}^{0}\right)$ and adsorption constant $\left(K_{\text {ads }}\right)$ are related by the equation

$\Delta G_{\mathrm{ad}}^{0}=-R T \ln \left(55.5 \mathrm{~K}_{\mathrm{ads}}\right)$.

The values of regression coefficient between the parameters $C / \theta$ and $C_{\text {inh }}$ for different concentrations of inhibitors in the presence and absence of pyoverdine gives the accuracy of findings.

If the value of $\Delta G_{\text {ads }}^{0}$ is $-40 \mathrm{~kJ} / \mathrm{mol}$ or more negative, it indicates the transfer of electron from the inhibitor to the metal surface forming a coordinate bond between them. $\Delta G_{\text {ads }}^{0}$ values are lower than above, for example, $-20 \mathrm{~kJ} / \mathrm{mol}$, leading to a weak electrostatic attraction between the charged inhibitor and the charged metal surface in the corrosion medium $[35,36]$.

Moreover, the negative value of $\Delta G_{\text {ads }}^{0}$ indicates the stability of the adsorbed layer on the steel surface and to some extent the spontaneity of the adsorption process. The perusal of $\Delta G_{\text {ads }}^{0}$ value ranging from -37 to $-43 \mathrm{~kJ} / \mathrm{mol}$ 


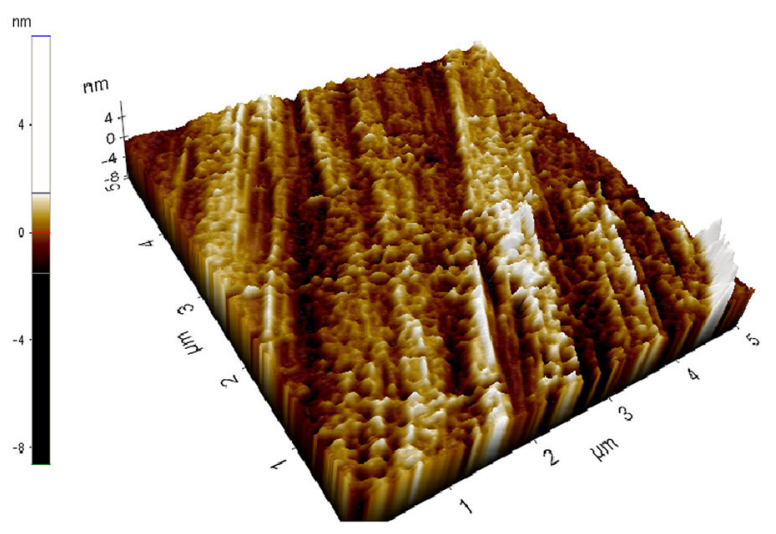

(a)

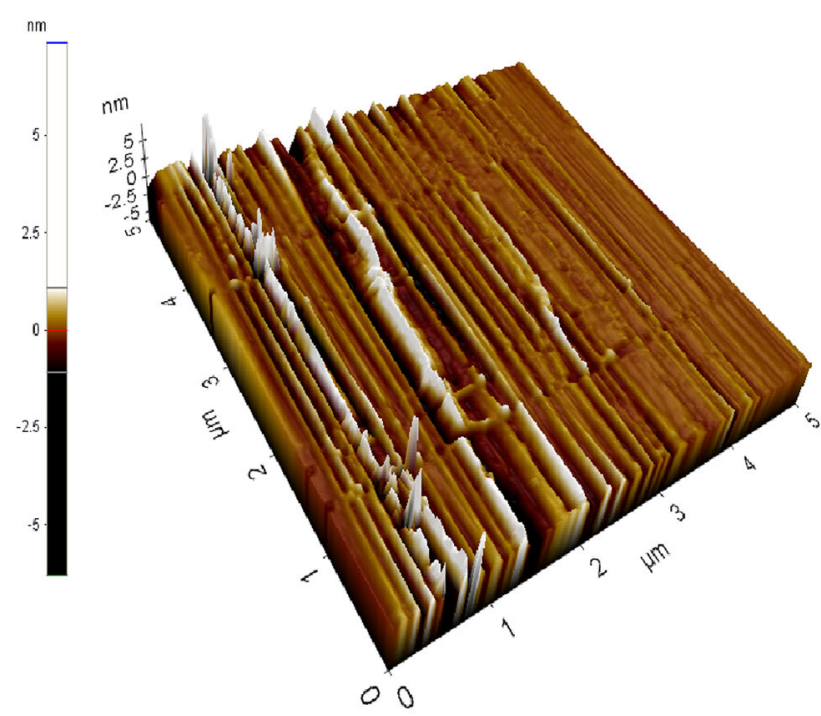

(b)

Fig. 12 AFM images: a mild steel in $0.5 \mathrm{M} \mathrm{HCl}$; b mild steel in $0.5 \mathrm{M} \mathrm{HCl}$ containing pyoverdine inhibitor

suggests that the adsorption of pyoverdine follows chemisorptions which are spontaneous in nature [37-40].

The surface coverage $(\theta)$ for different concentrations of pyoverdine was calculated, and it was plotted against the concentration of pyoverdine $\left(C_{\mathrm{inh}}\right)$ and $C / \theta$. The plot for $303 \mathrm{~K}$ obeying Langmuir model shown in Fig. 10a was more appropriate than those for 308 and $313 \mathrm{~K}$ obeying Temkin isotherm, $\log C_{\text {inh }}$ against $\theta$, which is shown in Fig. 10b.

\subsection{Surface Characterization}

The SEM micrographs of mild steel also support the findings. Figure 11a shows the SEM images of bare mild steel specimen with comparatively smooth surface. After immersion in the corrosive medium, the metal surface seems to be highly damaged which is shown in Fig. $11 \mathrm{~b}$.
The corrosion inhibition action of pyoverdine is clear from Fig. 11c which shows the mild steel surface exposed to $0.5 \mathrm{M} \mathrm{HCl}$ containing pyoverdine. The metal surface and roughness values look more or less similar for bare metal surface and metal surface exposed in medium containing pyoverdine again strongly suggest the formation of a protective layer by the inhibitor on the metal surface.

\subsection{Atomic Force Microscopy}

In order to further confirm the corrosion inhibition effect of the inhibitor, the surface morphology of the specimen was examined by AFM measurement. It gives a clear picture of acid corrosion and the formation of surface roughness within the presence and absence of pyoverdine. The surface topography was examined, and the results are presented as 3D images as shown in Fig. 12a, b. It is evident from the AFM images that the average roughness produced in aggressive corrosion mechanism is decreased to a significant extent when exposed to inhibited medium for the same exposure period. The decrease in roughness can be attributed to the formation of a thick monolayer of pyoverdine on mild steel surface [41].

The average roughness of mild steel coupons immersed in $0.5 \mathrm{M} \mathrm{HCl}$ was noted as $0.547 \mathrm{~nm}$ (Fig. 12a). It is clear that the electrode material was damaged due to the direct reaction of acid solution. However, the close inspection of the next picture exhibits the action of PVD on the mild steel surface. Herein, we can observe an average roughness of $0.309 \mathrm{~nm}$ (Fig. 12b). Hence, we can conclude that the mild steel specimen is effectively protected by the ecofriendly, biodegradable and naturally occurring molecule pyoverdine.

\section{Conclusions}

(1) In the present study, we project the first ever report on pyoverdine obtained from animal extract act as green inhibitor for mild steel. It is an excellent corrosion inhibitor for mild steel $-\mathrm{HCl}$ system through adsorption interaction.

(2) The values obtained from EIS measurements runs parallel with potentiodynamic polarization studies. There is a linear relation exists between the inhibition efficiency and concentration of pyoverdine.

(3) The potentiodynamic polarization measurements indicate that the pyoverdine performs as a mixed type inhibitor at three studied temperature regions such as 303,308 and $313 \mathrm{~K}$, respectively.

(4) The adsorption isotherm obeys the Langmuir adsorption on $303 \mathrm{~K}$ and Temkin adsorption at 308 and $313 \mathrm{~K}$. Chemisorption occurs at room temperature 
and physisorption at higher temperature. The high negative value of $\Delta G_{\text {ads }}^{0}$ indicates that pyoverdines can be adsorbed on mild steel surface by chemical mechanism and also the spontaneity of the adsorption process.

(5) SEM and AFM studies also confirm the formation of protective film on the surface of mild steel in $0.5 \mathrm{M}$ $\mathrm{HCl}$ solution.

\section{References}

1. Niu L, Zhang H, Wei FH, Wu SX, Cao XL, Liu PP (2005) Corrosion inhibition of iron in acidic solutions by alkyl quaternary ammonium halides: correlation between inhibition efficiency and molecular structure. Appl Surf Sci 252:1634-1642

2. Zhao J, Chen G (2012) The synergistic inhibition effect of oleicbased imidazoline and sodium benzoate on mild steel corrosion in a $\mathrm{CO}_{2}$-saturated brine solution. Electrochim Acta 69:247-255

3. Umoren SA, Ogbobe O, Igwe IO, Ebenso EE (2008) Inhibition of mild steel corrosion in acidic medium using synthetic and naturally occurring polymers and synergistic halide additives. Corros Sci 50:1998-2006

4. Mohsenifar F, Jafari H, Sayin K (2016) Investigation of thermodynamic parameters for steel corrosion in acidic solution in the presence of $N, N^{\prime}$-bis(phloroacetophenone)-1,2 propanediamine. J Bio Tribo Corros 2:1. doi:10.1007/s40735-015-0031

5. Ma HY, Chen SH, Yin BS, Zhao SY, Liu XQ (2003) Impedance spectroscopic study of corrosion inhibition of copper by surfactants in the acidic solutions. Corros Sci 45:867-882

6. Anupama KK, Shainy KM, Joseph A (2016) Excellent anticorrosion behavior of ruta graveolens extract (RGE) for mild steel in hydrochloric acid: electro analytical studies on the effect of time temperature and inhibitor concentration. J Bio Tribo Corros. doi: 10.1007/s40735-016-0032-5

7. Stupnišek-Lisac E, Berković-Salajster K, Vorkapić-Furac J (1988) An investigation of the efficiency of several organic descaling inhibitors. Corros Sci 28:1189-1202

8. Radojčić I, Berković K, Kovač S, Vorkapić-Furac J (2008) Natural honey and black radish juice as tin corrosion inhibitors. Corros Sci 50:1498-1504

9. Meyer JM (2000) Pyoverdines: pigments, siderophores and potential taxonomic markers of fluorescent Pseudomonas species. Arch Microbiol 174:135-142

10. McWhirter MJ, Philip JB, Iain L Lamont, AJ McQuillan (2003) Siderophore-mediated covalent bonding to metal (oxide) surfaces during biofilm initiation by Pseudomona saeruginosa bacteria. Langmuir 19:3575-3537

11. El-Etre AY (1998) Natural honey as corrosion inhibitor for metals and alloys. I copper in neutral aqueous solution. Corros Sci 40:1845-1850

12. El-Etre AY, Abdallah M (2000) Natural honey as corrosion inhibitor for metals and alloys II C-steel in high saline water. Corros Sci 42:731-738

13. Yee YJ (2004) Green inhibitors for corrosion control: a study on the inhibitive effects of extracts of honey and Rosmarinus officinalis L. (Rosemary) Thesis University of Manchester Institute of Science and Technology

14. Radojčić I, Berković K, Kovač S, Vorkapić-Furac J (2008) Natural honey and black radish juice as tin corrosion inhibitors. Corros Sci 50:1498-1504
15. Upritchard HG, Yang J, Bremer PJ, Lamont IL, McQuillan AJ (2007) Adsorption to metal oxides of the Pseudomonas aeruginosa siderophore pyoverdine and implications for bacterial biofilm formation on metals. Langmuir 23:7189-7195

16. Lopper JE, Buyer JS (1991) siderophores in microbial interactions on plant surfaces. Mol Plant Microbe Interact 4:5-13

17. Prive F, Combes S, Caquil L, Farizon Y, Enjalbert F, TroegelerMeynadier A (2010) Temperature and duration of sunflower oil affect ruminal biohydrogenation of linolic acid in vitro. J Diary Sci 93:711-722

18. Unni KN, Priji P, Geoffroy VA, Doble M, Benjamin S (2014) Pseudomonas aeruginosa BUP2-a novel strain isolated from Malabari Goat Produces Type 2 Pyoverdine. Adv Biosci Biotechnol 5:874-885

19. Lamont IL, Beare PA, Ochsner U, Vasil AI, Vasil ML (2002) Siderophore-mediated signalling regulates virulence factor production in pseudomonas aeruginosa. Proc Natl Acad Sci USA 99:7072-7077

20. Wendenbaum S, Demange P, Dell A, Meyer JM, Abdullah MA (1983) The structure of pyoverdine Pa the siderophore of Pseudomonas aeruginosa. Tetrahedron Lett 44:4877-4880

21. Jiang W, Saxena A, Song B, Ward BB, Beveridge TJ, Myneni SCB (2004) Elucidation of functional groups on gram-positive and gram-negative bacterial surfaces using infrared spectroscopy. Langmuir 20:11433-11442

22. Lopez DA, Simison SN, de Sanchez SR (2003) The influence of steel microstructure on $\mathrm{CO}_{2}$ corrosion EIS studies on the inhibition efficiency of benzimidazole. Electrochim Acta 48:845-854

23. Laibinis PE, White sides GM (1992) Self-assembled monolayers of $n$-alkanethiolates on copper are barrier films that protect the metal against oxidation by air. J Am Chem Soc 114:9022-9027

24. Quan Z, Chen W, Zhao S, Ma H (2001) Self-assembled monolayers of Schiff bases on copper surfaces. Corros Sci 57:195-201

25. Zhao J, Chen G (2012) The synergistic inhibition effect of oleicbased imidazoline and sodium benzoate on mild steel corrosion in a $\mathrm{CO}_{2}$-saturated brine solution. Electrochim Acta 69:247-255

26. Ozcan M, Dehri I (2004) Electrochemical and quantum chemical studies of some sulphur-containing organic compounds as inhibitors for the acid corrosion of mild steel. Prog Org Coat 51:181-187

27. Doner A, Kardas G (2011) $\mathrm{N}$-Aminorhodamine as an effective corrosion inhibitor for mild steel in $0.5 \mathrm{M} \mathrm{H}_{2} \mathrm{SO}_{4}$. Corros Sci 53:4223-4232

28. MoradM S (2007) Effect of Sulfur-containing amino acids on the corrosion of mild steel in Sufide- polluted sulfuric acid solutions. J Appl Electrochem 37:1191-1200

29. Li W, He Q, Zhang S, Pei C, Hou B (2008) Some new Triazole derivatives as inhibitors for mild steel corrosion in acidic medium. J Appl Electrochem 38:289-295

30. Pavithra MK, Venkatesha TV, Punith Kumar MK, Tondan HC (2012) Inhibition of mild steel corrosion by Rabeprazole sulfide. Corros Sci 60:104-111

31. Che W, Luo HQ, Li NB (2011) Inhibition effects of 2,5-dimercapto-1,3,4-thiadiazole on the corrosion of mild steel in sulphuric acid solution. Corros Sci 53:3356-3365

32. Benedetti AV, Sumodjo PTA, Nobe K, Cabot PL, Proud WG (1995) Electrochemical studies of copper, copper-aluminium and copper-aluminium-silver alloys: impedance results in $0.5 \mathrm{M}$ $\mathrm{NaCl}$. Electrochim Acta 40:2657-2668

33. Oguzie EE, Okolue BN, Ebenso EE, Onuoha GN, Onuchukwu AI (2004) Evaluation of the inhibitory effect of methylene blue dye on the corrosion of aluminium in hydrochloric acid. Mater Chem Phys 87:394-401

34. Ikeda O, Goto F, Tamura H (1981) Adsorption behaviour of $\mathrm{N}$-containing heterocycles at a mercury/water interface. Bull Chem Soc Jpn 54:3146-3151 
35. El Nemr A, Moneer AA, Khaled A, El Sikaily A, El-Sai GF (2014) Modeling of synergistic halide additives' effect on the corrosion of aluminum in basic solution containing dye. Mater Chem Phys 144:139-154

36. Dhar HP, Conway BE, Joshi KM (1973) on the form of adsorption isotherms for substitutional adsorption of molecules of different sizes. Electrochim Acta 18:789-798

37. El-Sayed M Sherif (2006) Effects of 2-amino-5-(ethylthio)-1,3,4thiadiazole on copper corrosion as a corrosion inhibitor in $3 \%$ $\mathrm{NaCl}$ solutions. Appl Surf Sci 252:8615-8619

38. Bastidas JM, Pinilla P, Cano E, Polo JL, Mignel S (2003) Copper corrosion inhibitor by triphenylmethane derivatives in Sulphuric acid media. Corros Sci 45:427-449
39. Mistry BM, Patel NS, Sahoo SK, Jauhari S (2012) Experimental and quantum chemical studies on corrosion inhibition performance of quinoline derivatives for MS in $1 \mathrm{M} \mathrm{HCl}$. Bull Mater Sci 35:459-469

40. Mistry BM, Jauhari S (2015) Studies on the inhibitive effect of (Z)-4-chloro- $N$-((2-chloroquinolin-3-yl)methylene)aniline Schiff baseon the corrosion of mild steel in $1 \mathrm{~N} \mathrm{HCl}$ solution. Res Chem Intermed 41:6289-6307

41. Eduok UM, Khaled M (2015) Corrosion inhibition for low-carbon steel in $1 \mathrm{M} \mathrm{H}_{2} \mathrm{SO}_{4}$ solution by phenytoin: evaluation of the inhibition potency of another "anticorrosive drug". Res Chem Intermed 41:6309-6324 